\title{
Analytical method development and validation of Secnidazole in the tablet dosage form by RP-HPLC method
}

Tanzina Sharmin, Mariyam Akter and Mohammad Salim Hossain

Department of Pharmacy, Noakhali Science and Technology University, Noakhali-3814, Bangladesh

\begin{abstract}
Objective of the present work is to develop and validate a simple, cost effective, sensitive and fast HPLC method for the analysis of Secnidazole. A Shimadzu HPLC system with Luna $5 \mu \mathrm{m} \mathrm{C}_{18}$ column is employed for the analysis using Methanol: $\mathrm{H}_{2} \mathrm{O}(60: 40$, v/v) as mobile phase. Signal from Secnidazole is detected at $310 \mathrm{~nm}$ by UV Spectrophotometer. The proposed method is fully validated and found to be linear over a workable drug concentration, accurate, precise and robust. This fast and inexpensive method is suitable for research laboratories as well as for quality control analysis in pharmaceutical industries.
\end{abstract}

Key Words: Secnidazole, HPLC, Nitroimidazole, pharmaceutical, Shimadzu, validation.

\section{INTRODUCTION}

Secnidazole is an antiprotozoal drug. It is a derivative of 5-nitromidazole which is closely related to Metronidazole (figure 1). It is a category of 6 Anti-infective drugs, Antiprotozoal drugs, Antiamebic and antigiardiasis drugs. It is of Synthetic origin and belongs to Nitroimidazole. Secnidazole belongs to Amebicides pharmacological group.

Secnidazole is used to treat intestinal ameobiasis, fiardiasis, trichomoniasis and bacterial vaginosis. These disease symptoms can be treated with a single once only dose of Secnidazole. Secnidazole does not differ from Metronidazole, being a nitroimidazole derivative. However, prolonged plasma half-life of Secnidazole makes it the first choice for treatment of many diseases (Gillis and Wiseman, 1996). Various method validations for Secnidazole has been developed using different analytical methods for the determination of Secnidazole in pharmaceutical dosage formulations (Misiuk, 2010, Farooqui et al., 2010, Bansode et al., 2013, Jain et al., 2014, Baraka et al., 2014). These methods are used either alone or in combination with other drugs. HPLC method is more suitable than others because operational pressures are significantly higher (50-350 bar) and requires very small sample amount to be separated (Shabir, 2003).

Among the existing methods for determination of Secnidazole in pharmaceutical dosage forms, most are time consuming, expensive, complex in nature and damage the susceptibly of the column (Alhalabi et al., 2012, Farooqui et al., 2010, Yanamandra et al., 2011). The aim of the present work was to attempt the development of new HPLC methods for Secnidazole which are superior to prior developed methods with respect to cost of analysis, analysis time, sensitivity and simplification.

Tanzina Sharmin and Mariyam Akter contributed equally to this work and should be considered as joint first authors

Corresponding Author:

Mariyam Akter, Lecturer

Department of Pharmacy

Noakhali Science and Technology University

Noakhali-3814, Bangladesh

E-mail: moni_mariyam@yahoo.com
When the method is developed it must be validated to check that it meets performance characteristics. Typical analytical characteristics used in method validation are accuracy, precision, specificity, detection limit, quantitation limit, linearity, and range and robustness. Further, the proposed method was validated as per ICH guideline (ICH, 2005).

\section{MATERIALS AND METHODS}

\section{Chemicals and reagents}

Pharmaceutical grade of Secnidazole was supplied as a generous gift from Incepta Pharmaceuticals Limited, Saver, Bangladesh, Secnidazole 1000mg (Secnid DS by Square Pharmaceuticals Ltd, Bangladesh) was procured from local market (Noakhali, Bangladesh). Methanol HPLC grade from Active Fine Chemicals Ltd, Bangladesh Methanol Reagent grade from Active Fine Chemicals Ltd, Bangladesh, HPLC grade water and Distilled-water were used.

Instrument used and Chromatographic conditions HPLC system compromised of Column Oven (Model: CT10ASvp Made by Shimadzu Corporation Japan), Prominence Liquid Chromatographs, (Model: LC20AT, Japan), Prominence Degassing unit (Model: DGU-20A3R, Japan) and Prominence UV/ VIS Detector (Model: SPD-20A,

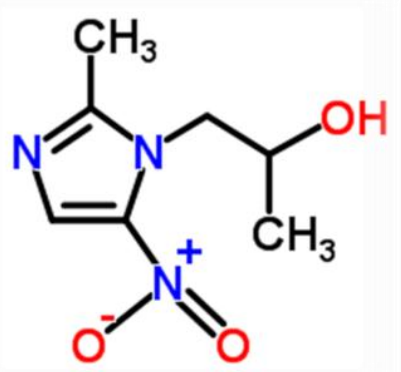

Figure 1: Chemical structure of Secnidazole. 


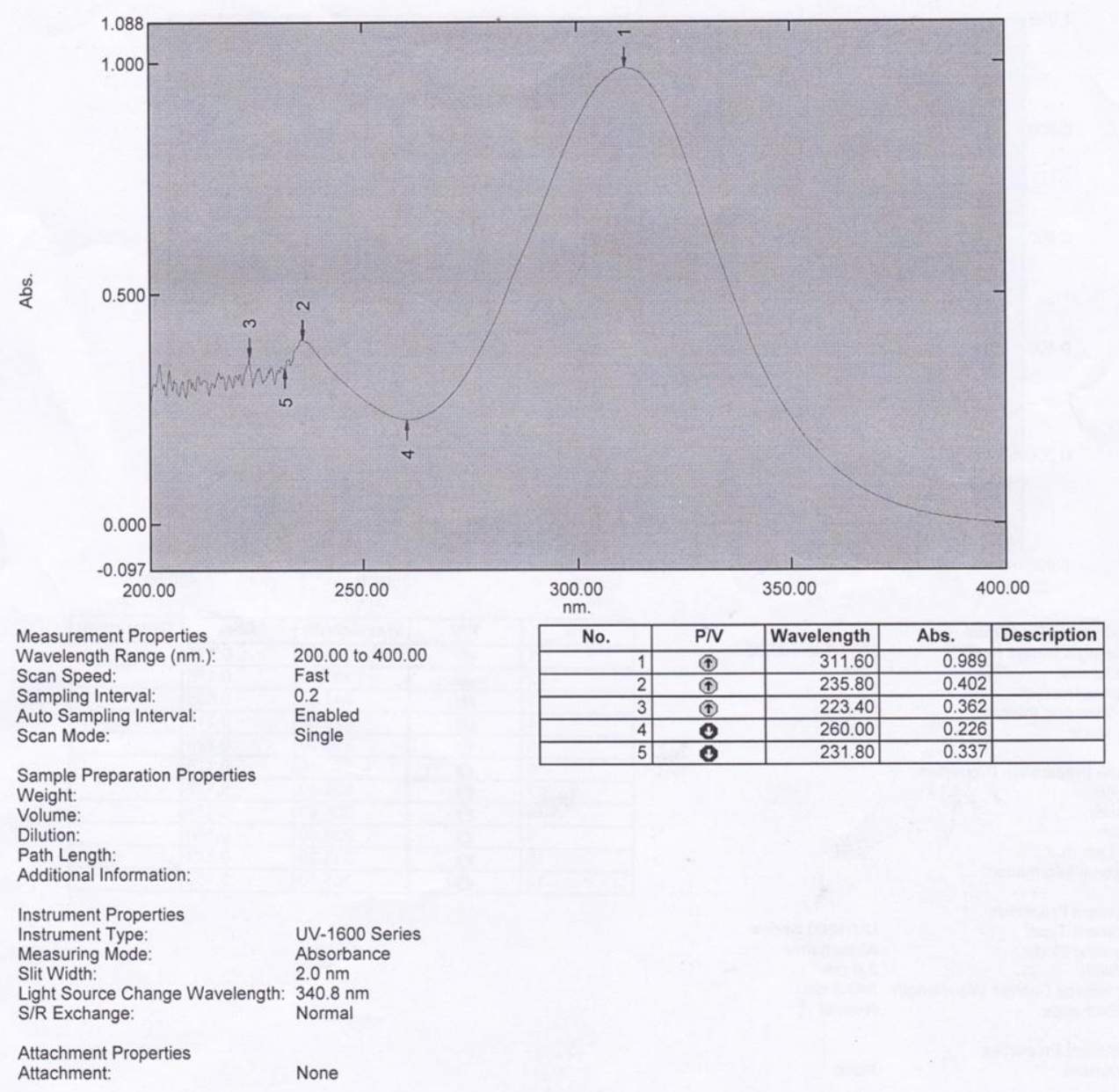

Figure 2: UV spectrum of Secnidazole.

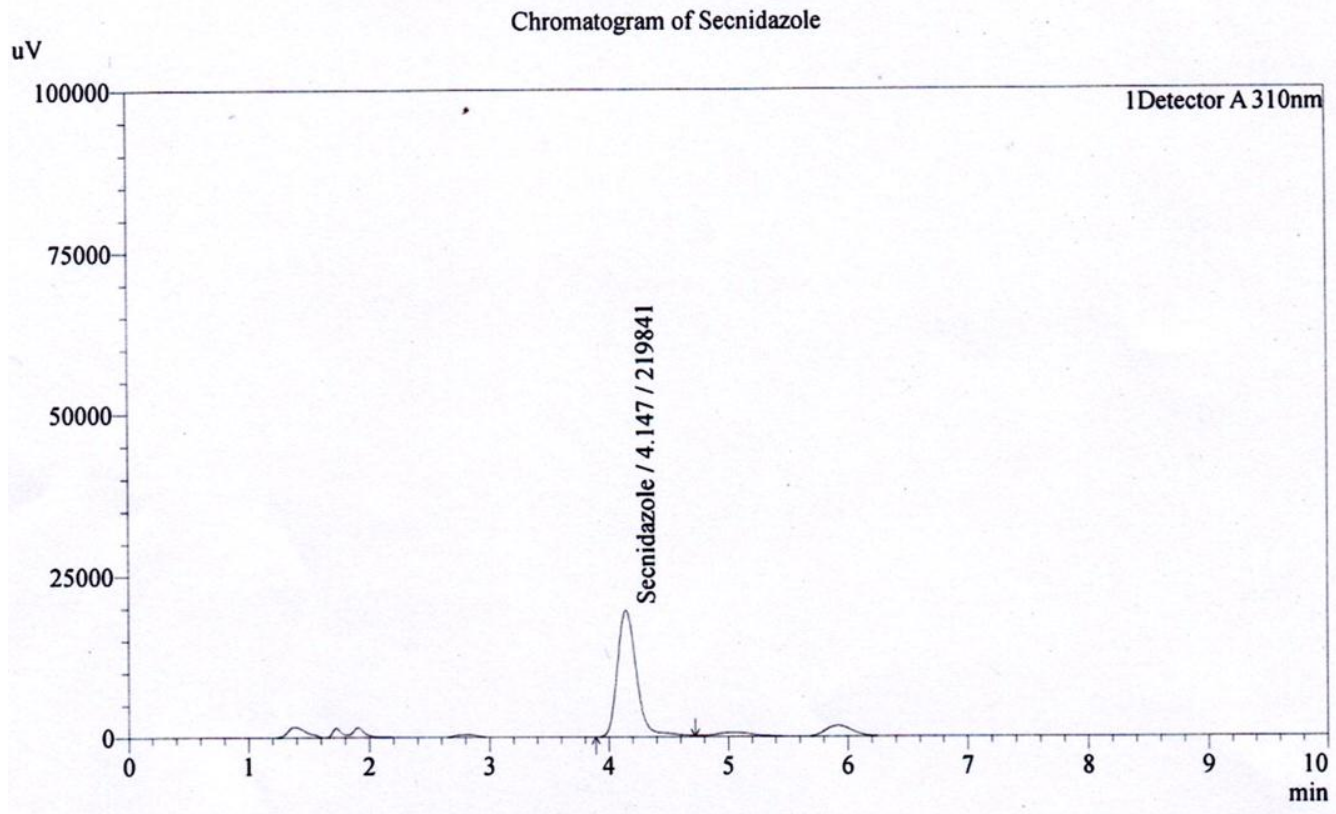

Figure 3: Typical Chromatogram of Secnidazole. 
Japan). The chromatographic separations were performed using Luna $5 \mu \mathrm{m} \mathrm{C}_{18} 100 \mathrm{~A}$ (Size $150 \times 4.60 \mathrm{~mm}$ ) as column, Methanol: $\mathrm{H}_{2} \mathrm{O}(60: 40, \mathrm{v} / \mathrm{v})$ as mobile phase, flow rate $1 \mathrm{ml} / \mathrm{min}$ with isocratic elution and retention time of $4.147 \mathrm{~min}$ etc. The wavelength $310 \mathrm{~nm}$ was detected by UV Spectrometer (Model: UV-1800, Made by Shimadzu Corporation) (figure 2).

\section{Standard and sample preparation}

An accurately weighed quantity of $25 \mathrm{mg}$ of Secnidazole was placed into a $100 \mathrm{ml}$ volumetric flask and dissolved in reagent grade methanol up to $100 \mathrm{ml}$. Then, $2 \mathrm{ml}$ were withdrawn in a $25 \mathrm{ml}$ volumetric flask. The volume was made with mobile phase to made final concentration of $20 \mu \mathrm{g} / \mathrm{ml}$. The solutions were passed through a $0.45 \mu \mathrm{m}$ nylon membrane filter before injection. To prepare sample solution, same procedure was followed to make the concentration of standard solution and sample solution same. Briefly, the average weight of 20 tablets was taken. Then these 20 tablets were grinded and an equivalent weight of $25 \mathrm{mg}$ of Secnidazole standard was taken from grinded powder. Accurately weighted sample was poured in a $100 \mathrm{ml}$ volumetric flask and about $60 \mathrm{ml}$ of methanol was added. Sample solution then was sonicated for 10 minutes. After 10 minutes volume of sample solution was made up to $100 \mathrm{ml}$ and then sample solution was filtered using Whatman filter paper. The dilution from this stock solution was same as standard solution.

\section{Method development and optimization}

For the simultaneous determination of Secnidazole with an intention to develop a precise, accurate, simple, rapid, sensitive and specific way, isocratic RP-HPLC method was optimized. Secnidazole was very soluble in the methanol, ethanol, chloroform, acetic acid and water. But methanol and water are easily available and low cost. So, different mobile phases were tried with different fractions of methanol and water. A satisfactory resolution was achieved using a mixture of methanol and water in the ratio of $60: 40(\mathrm{v} / \mathrm{v})$. The optimum wavelength for detection of Secnidazole was $310 \mathrm{~nm}$. The flow rate of Secnidazole was $1 \mathrm{ml} / \mathrm{min}$ at ambient temperature for column oven $\left(25^{\circ} \mathrm{C}\right)$. The injection volume was $20 \mu \mathrm{L}$ and run time was $10 \mathrm{~min}$. The retention time of Secnidazole was observed at $4.147 \mathrm{~min}$ (figure 3 ).

System Suitability and Method validation

All the system suitability parameters were assessed as per ICH guidelines (ICH, 2005).

\section{RESULTS AND DISCUSSION}

\section{Linearity and range}

The linear regression data for the calibration curves showed good linear relationship over the concentration range of $20-60 \mu \mathrm{g} / \mathrm{ml}$ for Secnidazole. Typically, the regression equations for the calibration curve was found to be $y=95882 x-2 E+06(r 2=0.990)$ for Secnidazole. The calibration curve was plotted by considering the peak areas(y) versus corresponding concentration(x) (figure 4, table 1).

Limit of detection (LOD) and limit of quantitation (LOQ) For this study, three replicates of analyte at lowest concentrations were measured and quantified. The equations are $\mathrm{LOD}=3.3 \times \sigma / \mathrm{S}$ and $\mathrm{LOQ}=10 \times \sigma / \mathrm{S}$ where, ' $\sigma$ ' is standard deviation of lowest three concentrations and ' $S$ ' is slope of linearity equation. The LOD and LOQ were $0.33 \mu \mathrm{g} / \mathrm{ml}$ and $0.99 \mu \mathrm{g} / \mathrm{ml}$ respectively (table 2 ).

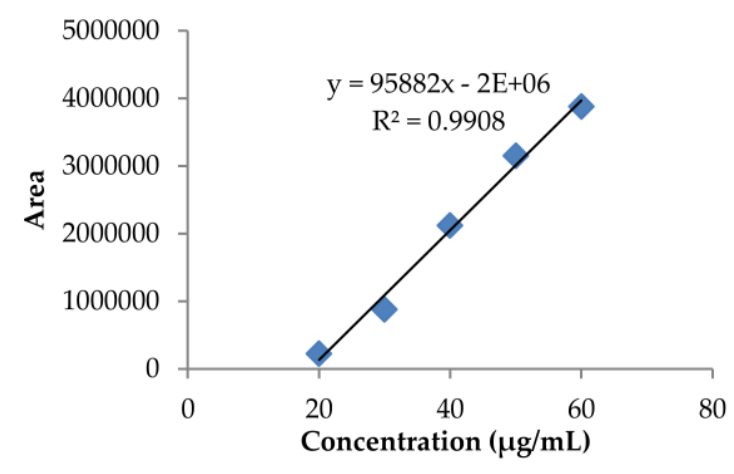

Figure 4: Linearity curve of Secnidazole.

Table 1: Linearity study of Secnidazole.

\begin{tabular}{cccccc}
\hline Sr. no. & $\begin{array}{c}\text { Concentration } \\
{[\mu \mathrm{g} / \mathrm{ml}]}\end{array}$ & Peak Area & Slope & Intercept & $\begin{array}{c}\mathbf{R}^{2} \\
\text { Value }\end{array}$ \\
\hline 1 & 20 & 219841 & & & \\
2 & 30 & 879906 & & & \\
3 & 40 & 2117130 & 95882 & 06 & 0.990 \\
4 & 50 & 3150969 & & & \\
5 & 60 & 3878387 & & & \\
\hline
\end{tabular}

Table 2: LOD and LOQ data.

\begin{tabular}{ccccccc}
\hline Sr. No. & $\begin{array}{c}\text { Conc. } \\
(\mu \mathrm{g} / \mathrm{ml})\end{array}$ & Area & $\sigma$ & $\mathrm{S}$ & $\begin{array}{c}\text { LOD } \\
(\mu \mathrm{g} / \mathrm{ml})\end{array}$ & $\begin{array}{c}\text { LOQ } \\
(\mu \mathrm{\mu} / \mathbf{m l})\end{array}$ \\
\hline 1 & 4 & 68942 & & & & \\
2 & 6 & 78654 & 9497.811 & 95882 & 0.33 & 0.99 \\
3 & 8 & 87936 & & & & \\
\hline
\end{tabular}

Table 3: Precision data.

\begin{tabular}{cccccccc}
\hline $\begin{array}{l}\text { Sr. } \\
\text { no. }\end{array}$ preparation & $\begin{array}{c}\text { Sample } \\
\text { wt. }(\mathbf{m g})\end{array}$ & $\begin{array}{c}\text { Area of } \\
\text { sample }\end{array}$ & $\begin{array}{c}\text { Assay } \\
\text { (mg) }\end{array}$ & $\begin{array}{c}\text { Average } \\
\text { value }\end{array}$ & SD & $\begin{array}{c}\text { \% } \\
\text { RSD }\end{array}$ \\
\hline 1 & Sample 1 & 29.00 & 217969 & 985.22 & & & \\
2 & Sample 2 & 29.03 & 217572 & 983.43 & & & \\
3 & Sample 3 & 29.20 & 216965 & 974.17 & 980.77 & 3.98 & 0.41 \\
4 & Sample 4 & 29.09 & 217492 & 980.89 & & & \\
5 & Sample 5 & 29.10 & 218340 & 982.53 & & & \\
6 & Sample 6 & 29.16 & 217892 & 978.35 & & & \\
\hline
\end{tabular}

Table 4: Robustness of Secnidazole.

\begin{tabular}{cccccccc}
\hline $\begin{array}{l}\text { Sr. } \\
\text { no }\end{array}$ & $\begin{array}{c}\text { Sample } \\
\text { preparation }\end{array}$ & $\begin{array}{c}\text { Sample } \\
\text { wt. (mg) }\end{array}$ & $\begin{array}{c}\text { Area of } \\
\text { sample }\end{array}$ & $\begin{array}{c}\text { Assay } \\
\text { (mg) }\end{array}$ & $\begin{array}{c}\text { Average } \\
\text { value }\end{array}$ & SD & $\begin{array}{c}\text { \% } \\
\text { RSD }\end{array}$ \\
\hline 1 & Sample 1 & 29.16 & 225931 & 980.54 & & & \\
2 & Sample 2 & 29.18 & 226889 & 984.70 & & & \\
3 & Sample 3 & 29.09 & 226524 & 985.38 & 982.44 & 4.09 & 0.42 \\
4 & Sample 4 & 29.15 & 224857 & 975.88 & & & \\
5 & Sample 5 & 29.20 & 226583 & 981.10 & & & \\
6 & Sample 6 & 29.12 & 226910 & 987.06 & & & \\
\hline
\end{tabular}

Table 5: Accuracy of Secnidazole.

\begin{tabular}{cccccc}
\hline Sample & $\begin{array}{c}\text { Area of } \\
\text { sample }\end{array}$ & $\begin{array}{c}\text { Theoretical } \\
\text { value }(\mathbf{m g})\end{array}$ & $\begin{array}{c}\text { Experimental } \\
\text { value }(\mathbf{m g})\end{array}$ & $\begin{array}{c}\text { \%o of } \\
\text { recovery }\end{array}$ & Mean \\
\hline $80 \%$ S -1 & 219277 & 831.96 & 831.15 & 99.90 & \\
$80 \%$ S -2 & 219577 & 831.96 & 831.52 & 99.94 & 99.93 \\
$80 \%$ S -3 & 219960 & 831.96 & 831.67 & 99.96 & \\
$100 \%$ S -1 & 223244 & 1039.94 & 1039.59 & 99.96 & \\
$100 \%$ S - 2 & 226533 & 1039.94 & 1039.32 & 99.94 & 99.95 \\
$100 \%$ S -3 & 229456 & 1039.94 & 1039.42 & 99.95 & \\
$120 \%$ S - 1 & 226889 & 1247.93 & 1247.46 & 99.96 & \\
$120 \%$ S - 2 & 227658 & 1247.93 & 1247.19 & 99.94 & 99.94 \\
$120 \%$ S-3 & 227387 & 1247.93 & 1247.11 & 99.93 & \\
\hline
\end{tabular}




\section{Precision}

The precision of the developed HPLC method was expressed in terms of percent relative standard deviation (\% RSD). At first, standard sample $(20 \mu \mathrm{g} / \mathrm{ml})$ was run for six times. After confirmation of system suitability parameters (number of theoretical plates, tailing factors etc.), six samples were injected. Then $\%$ RSD was calculated as 0.406 (table 3 ). \% RSD values less than 2 , revealed high precision of the method.

\section{Robustness}

There are different ways to check the robustness of methods such as variations of $\mathrm{pH}$ in a mobile phase, variations in mobile phase composition, different columns (different lots and/or suppliers), flow rate, detection wavelength, temperature etc. In this study, standard deviation of peak areas was calculated by changing two parameters. Temperature was increased to $30^{\circ} \mathrm{C}$ and flow rate was changed to $0.8 \mathrm{ml} / \mathrm{min}$. \% RSD was found to be $0.416(<2)$ (table 4). Being less than 2, the values of \% RSD indicated the robustness of the method. It was observed that there were no marked changes in chromatograms.

\section{Accuracy}

Accuracy was performed in triplicate after spiking pure drug equivalent to 80,100 , and $120 \%$ of the standard concentration of Secnidazole $(20 \mu \mathrm{g} / \mathrm{ml})$. Recovery was found in the range from $99.93-99.95 \%$. The recovery of Secnidazole by proposed method is satisfactory as percent of relative standard deviation is not more than $\pm 2.0 \%$ and mean recovery between 98.0 - 102.0\% (table 5).

\section{CONCLUSION}

The developed HPLC method for the qualification of Secnidazole was performed in mobile phase methanol: water $(60: 40, \mathrm{v} / \mathrm{v})$. The modalities adopted in experiment were successfully validated as per ICH guidelines. It is thus inferred that this newly developed method was found to be accurate, simple, precise, and reproducible. The current method can be conveniently applied for quality control analysis in industry. The short run time of this method will significantly reduce the analysis time and cost.

\section{REFERENCES}

Alhalabi, Z., Khayat, M.A.A., Haldar, S. (2012) Separation and assay of antiprotozoal imidazole derivatives (metronidazole, tinidazole secnidazole) By RP-HPLC. International Journal of Pharmaceutical Science Review and Research, Volume 13, Issue 1, Pages 1-18.

Bansode, A.S., Shelke, V. D. and Jamdade, P.R. (2013) Stability indicating UV-spectrophotometric method for Secnidazole in bulk and pharmaceutical formulation. International Journal of Universal Pharmacy and Bio Sciences, Volume 2, Issue 4, Pages 19-26.

Baraka, M.M., Elsadek, M.E. and Ibrahim, A.M. (2014) HPLC method for the simultaneous determination of Secnidazole, Omeprazole and Amoxicillin mixture in pure forms and pharmaceutical formulations Asian Journal of Pharmaceutical Analysis And Medicinal Chemistry, Volume 2, Issue 4, Pages 197-207.

Farooqui, N.A., Smith, A., Sharma, H.K and Manavalan, R. (2010) Analytical Method Development and Validation of Secnidazole Tablets by RP-HPLC. Journal of Pharmaceutical Sciences and Research, Volume 2, Issue 7, Pages 412-416.

Gillis, J.C. and Wiseman, L.R. (1996) Secnidazole. A review of its antimicrobial activity, pharmacokinetic properties and therapeutic use in the management of protozoal infections and bacterial vaginosis. Drugs, Volume 51, Pages 621-638. [DOI]

ICH. (2005) International conference on harmonization of technical requiremnts for registration of pharmaceuticals for human use. ICH Harmonised Triparatite Guideline, Validation and Analytical Procedures: Text and Methodology Q2(R1)

Jain P.S., Lohar, T.R., Kale, N.L and Surana, S.J. (2014) Development and validation of stability-indicating HPTLC method for estimation of secnidazole in bulk drug and pharmaceutical dosage form. Journal of Advanced Drug Delivery, Volume 1, Issue 4, Pages 144-156

Misiuk, W. (2010) The role of assay methods in characterizing the quality of bulk pharmaceuticals. Journal of Pharmacy and Bioallied Science, Volume 2, Issue 2, Pages 88-92. [DOI]

Shabir, G.A. (2003) Validation of HPLC Methods for Pharmaceutical Analysis: Understanding the Differences and Similarities between Validation Requirements of the U.S. FDA, USP and ICH. Journal of Chromatography, Volume 987, Pages 57-66. [DOI]

Yanamandra, R., Chaudhary, A., Bandaru, S.R., Sastry, C.S.P., Patro, B. Murthy, Y.L.N and Ramaiah, P.A. (2011) Development of a RP-UPLC method for the simultaneous analysis of Secnidazole, Fluconazole, and Azithromycin: Application in pharmaceuticals and human serum. International Journal of PharmTech Research , Volume 3, Issue 2, Pages 1198-1207. 